\title{
A Subsegmental Correspondence Approach to Contour Tone (Dis)Harmony Patterns
}

\author{
Stephanie S Shih ${ }^{1}$ and Sharon Inkelas ${ }^{2}$ \\ ${ }^{1}$ Stanford University and ${ }^{1,2}$ University of California, Berkeley
}

\section{Introduction}

This paper addresses a long-standing question in the phonological literature: are "contour tones" (e.g. LH, 35) single units or sequences? Similar questions can, and have, been posed regarding so-called "contour segments" like ${ }^{n} d$ or $t$. The debate over whether contours of this kind are single units or sequences derives from the behavioral duality they exhibit. While contours sometimes behave as units, at other times their parts act independently.

The proposal advanced in this paper is termed $\mathrm{ABC}+\mathrm{Q}$. This paper introduces Q-theory, a new subdivided, quantized representation that allows contour duality to be referenced, and embeds Q-theory into Agreement by Correspondence (ABC; Hansson 2001, Rose \& Walker 2004). The result, ABC+Q, is a highly flexible and principled grammatical theory of the behavior of contours. $A B C+Q$ marries the representational strength of previous approaches (e.g., Autosegmental Phonology, Aperture Theory, Articulatory Phonology) with the locality and similarity design features of $\mathrm{ABC}$ to capture at once the unity and internal complexity of segments.

The focus of this paper is tone and tonal contours. In other work, we extend the $\mathrm{ABC}+\mathrm{Q}$ approach to segmental contours (Inkelas \& Shih 2013a). Taken together, this body of work unites the treatment of tone and segmental phonology, achieving one of the original goals set out by Autosegmental Phonology.

\section{Q-theory: Quantized segmental subdivisions}

The main claim of $\mathrm{Q}$ theory is that each segment $(Q)$ is subdivided into temporally-ordered, quantized subsegments, termed $q$. Example (1) portrays what we assume is a standard subdivision into three parts. In the case of vowels, the middle portion can be interpreted as the target vowel, while the initial and final portions represent the transitions into and out of the vowel, respectively. For vowels, a tripartite structure permits straightforward representations of triple tone contours as well as triphthongs. For consonants, the tripartite structure represents the closure transition, the target construction, and the release transition; this tripartite structure permits a straightforward account of triple contours, such as prenasalized affricates:

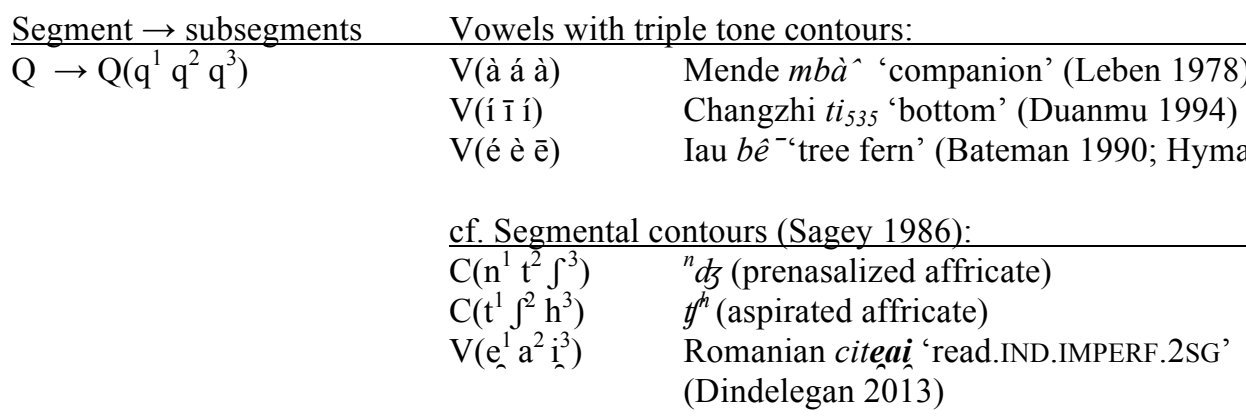

The tripartite $\mathrm{Q}\left(\mathrm{q}^{1} \mathrm{q}^{2} \mathrm{q}^{3}\right)$ structure is a purely phonological representation, but one which is phonetically grounded. The individual $q$ subsegments correspond coarsely to the segment-internal 'landmarks' of Gafos (2002:271). The $\mathrm{Q}\left(\mathrm{q}^{1} \mathrm{q}^{2} \mathrm{q}^{3}\right)$ structure itself can be compared to the 'tonal complexes' of Akinlabi \&

\footnotetext{
* For discussion on various stages of this work, we thank Larry Hyman, Florian Lionnet, Jaye Padgett, Rob Podesva, Donca Steriade, Meghan Sumner, John Sylak-Glassman, Kie Zuraw, and audiences at Berkeley, the 2013 Manchester Phonology Meeting, and Phonology 2013 at Amherst. The authors' names are arranged in reverse alphabetical order.
}

(C) 2014 Stephanie S Shih and Sharon Inkelas

Proceedings of Phonology 2013

Completed February 14, 2014 
Liberman (2001) and to the Aperture node complexes developed by Steriade (1993; 1994), who focuses on phonologically modeling the ordered 'closure' and 'release' phases of consonants. Q theory can be interpreted as a significant expansion on Steriade's idea (see below).

The assumed maximum of three $q$ subsegments per $Q$ segment is empirically motivated by the fact that tonal contours on single segments, moras, or syllables — the traditional 'tone-bearing units' - are overwhelmingly composed of either 2 or 3 tone levels. This generalization is captured on the assumption that any given $q$ is featurally uniform. A $Q$ segment is characterized as exhibiting a contour if two or more of its component $q$ subsegments bear different tones.

The prediction of $\mathrm{Q}$ theory is that 4-tone contours will not occur. Certainly such contours are typologically rare (e.g., Qiyang: see Hu 2011; or Korean aegyo markers: Moon, in prep). In some, if not all cases, 4-tone contours are accompanied by phonological lengthening of the host segment (Zhang 2001; et seq.). This follows from the assumption that a single, short $Q$ has only 3 subsegments. Lengthening (geminating) a vocalic $Q$ presumably doubles the number of $q$ subsegments which are available to bear tone $^{1}$. Q theory also predicts the existence of 2-part or 3-part contour segments, and the nonexistence of 4part contours. This prediction appears to be correct, with the possible exception of Mazatec $\left[{ }^{\mathrm{n}} \mathrm{t} \mathrm{h}^{\mathrm{h}}\right]$ (Pike \& Pike 1947; Steriade 1994). See, however, Golston \& Kehrein (1998) for an alternative analysis of Mazatec that does not posit a 4-part segment.

Phonological evidence for tripartite $q$ structures comes not only from 3-part contours but also from 2part contours, whose alignment with respect to the three $q$ 's of a given $Q$ is predicted in $\mathrm{Q}$ theory to be potentially contrastive. Remijsen (2013) argues that the segment-internal alignment of HL tonal contours in Dinka exhibits precisely the sort of contrast Q theory predicts. According to Remijsen, Dinka contrasts a late-aligned HL contour, which he terms 'Fall', with an early-aligned contour, which he terms Low $_{\text {Fall }}$. In terms of Q theory, the contrast would be modeled as follows. The initial $q$ in both cases is $\mathrm{H}$; the final $q$ is L. At issue is the tonal specification on the middle $q$ : Fall $=\mathrm{Q}\left(\mathrm{H}^{1} \mathrm{H}^{2} \mathrm{~L}^{3}\right)$ versus $\mathrm{Low}^{\mathrm{Fall}}=\mathrm{Q}\left(\mathrm{H}^{1} \mathrm{~L}^{2} \mathrm{~L}^{3}\right)$.

Q theory exhibits multiple points of contact with Autosegmental Theory (Leben 1973; Goldsmith 1976), Articulatory Phonology (Browman \& Goldstein 1989, et seq.; Gafos 2002; a.o.), Aperture Theory (Steriade 1993; 1994), and proposals for multiple docking sites on TBU (e.g., Morén \& Zsiga 2006). There are, however, a number of differences between $\mathrm{Q}$ theory and these predecessors.

Like Aperture Theory and Articulatory Phonology, Q theory posits phonetically-grounded temporal subdivisions with different featural makeup for (some) segments. In Aperture Theory, however, only consonants are subdivided, and they are subdivided into only two parts, as opposed to the the three subdivisions all segments have in Q theory.

Aperture theory (Steriade 1993; 1994)

$\left[\mathrm{t}^{\mathrm{h}}\right]$

$[\mathrm{s}]$

$$
\begin{array}{cc}
\mathrm{A}_{0} & \mathrm{~A}_{\text {rel }} \\
\mathrm{l} & \mathrm{l} \\
\mathrm{t} & \mathrm{h}
\end{array}
$$$$
\mathrm{A}_{\text {fric }}
$$

$$
\begin{aligned}
& \text { cf. Q theory } \\
& Q\left(t^{1} t^{2} h^{3}\right) \\
& Q\left(s^{1} s^{2} s^{3}\right)
\end{aligned}
$$

Unlike Aperture Theory, Q theory explicitly includes tone as well as segmental features. In Q theory, the notion of 'segment' is explicit (the $Q$ of $\mathrm{Q}\left(\mathrm{q}^{1} \mathrm{q}^{2} \mathrm{q}^{3}\right)$ ), while in Aperture Theory, 'segment' is not represented directly, but is the interpretation of a series of A positions. This distinction is important because, as is argued below, reference to the segment as a whole is crucial to capturing contour behavior.

Like Autosegmental Theory, Q theory allows independent, sequenced feature values within a single segment. Unlike Autosegmental Theory, however, Q theory does not permit contouring on a given subsegment. Many-to-one linking does not exist. Rather, each subsegment in Q theory is featurally uniform.

\footnotetext{
${ }^{1}$ This might predict the possibility of a 6-way tone contour on a single long vowel, which seems unlikely. However, it is also possible that a phonologically long segment doubles only the middle (target constriction) $q$, not the transitional $q$ subsegments on either end of the segment, thus yielding $4 q$ 's. The representation of phonologically long segments in $\mathrm{Q}$ theory is a matter for future research.
} 


\section{Behavior of contours: A working typology}

A signature of $\mathrm{Q}$ theory is its ability to capture the full range of contour behavior, from the unity of contours to the independence of their individual components. As mentioned, we focus here on tone. The sketch typology in (3) illustrates the wide range of contour tone behavior. Contour tones can agree as whole $Q$ units, as in Changzhi (3a). Parts of contour tones, represented via $q$, can also agree across otherwise differing $Q$ 's, as in Yoruba (3c). The same patterns obtain in tonal dissimilation: Pingyao exhibits whole contour dissimilation (3b), while Tianjin exhibits partial contour tone dissimilation (3d):

Examples of tone contour duality:

\begin{tabular}{|c|c|c|}
\hline & Whole segment: $Q$ & Subsegment: $q$ \\
\hline Harmony & $\begin{array}{l}\text { a. Changzhi whole contour tone copying } \\
\text { (Duanmu 1994; a.o.): } \\
/ \text { kuə }_{213}-\mathrm{t \partial}_{535}^{2} / \rightarrow\left[\mathrm{kuə}_{213}-\mathrm{to}_{213}^{2}\right] \text { 'pan, dim.' }\end{array}$ & $\begin{array}{l}\text { c. Yoruba partial assimilation (Akinbiyi \& } \\
\text { Liberman 2001): } \\
\text { /rárà/ } \rightarrow \text { [rárâ] 'elegy' }\end{array}$ \\
\hline Disharmony & $\begin{array}{l}\text { b. Pingyao: whole contour dissimilation } \\
\text { (Chen 1992; Yip 2002): } \\
\left.\text { /hai }{ }_{35} \text { bing }_{35} / \rightarrow \text { [hai }{ }_{53} \text { bing }_{35}\right] \text { 'become ill' }\end{array}$ & $\begin{array}{l}\text { d. Tianjin: subsegments dissimilate across } \\
\sigma \text { boundary (Chen 1985; a.o.): } \\
/ \mathrm{fei}_{\mathrm{L}}-\mathrm{ji} \mathrm{i}_{\mathrm{L}} / \rightarrow\left[\mathrm{fei}_{\mathrm{LH}} \cdot \mathrm{ji} \mathrm{i}_{\mathrm{L}}\right] \text { 'airplane' }\end{array}$ \\
\hline
\end{tabular}

Analogs to the behaviors of contour tones are found in contour segments, as shown in the example typology in (4) (Inkelas \& Shih 2013a). Just as in tone, contour segments also exhibit schizoid behavior: sometimes the entire contour acts as a unit and, at other times, the constituent subsegmental parts of the contours interact with one another, independent of the whole.

Analogs to (3) in the segmental domain:

\begin{tabular}{|c|c|c|}
\hline & Whole segment: $Q$ & Subsegment: $q$ \\
\hline Harmony & $\begin{array}{l}\text { a. Ngbaka: nasals agree in contour status } \\
\left({ }^{* \mathrm{~N}} \mathrm{C} \ldots \mathrm{N},{ }^{* \mathrm{~N}} \mathrm{C} \ldots \mathrm{C} \text {; but }{ }^{\mathrm{N}} \mathrm{C} \ldots{ }^{\mathrm{N}} \mathrm{C}, \mathrm{N} \ldots \mathrm{C} \text { OK) }\right. \\
\text { (Hansson } 2001 ; \text { Rose \& Walker } 2004) \\
\left.\left[{ }^{\mathrm{m}} \mathrm{b} \varepsilon \varepsilon^{\mathrm{m}} \mathrm{b} \varepsilon\right] \text { 'snail', [nanc] 'today'; } *{ }^{*} \text { becm } \varepsilon\right]\end{array}$ & $\begin{array}{l}\text { c. Samala (Ineseño Chumash): sibilant } \\
\text { subsegments agree in anteriority } \\
\text { (Applegate 1972; Hansson 2001) } \\
\left.\text { /s-api-t } \int^{\text {h }} \text { o-it/ } \rightarrow \text { [ } \text { apit } \int^{\text {h }} \text { olit }\right] \\
\text { 'I have a stroke of good luck' }\end{array}$ \\
\hline Disharmony & $\begin{array}{l}\text { c. Gurindji: }{ }^{\mathrm{N}} \mathrm{C} \text { contours dissimilate } \\
\text { (McConvell 1988; Rose \& Walker 2004) } \\
\text { /winji-nka/ } \rightarrow \text { [winjika] 'spring-LOC' }\end{array}$ & $\begin{array}{l}\text { d. Basque: stop/affricate dissimilates to } \\
\text { fricative preceding a stop (Hualde 1987) } \\
\text { /hits }+ \text { tegi/ } \rightarrow \text { [histegi] 'dictionary' }\end{array}$ \\
\hline
\end{tabular}

\section{Previous theoretical approaches to contours in harmony}

The previous phonological literature provides two very different approaches to harmony: the venerable Autosegmental Phonology (Leben 1973; Goldsmith 1976) and the newer Agreement by Correspondence (ABC; Walker 2000; Hansson 2001; Rose \& Walker 2004; a.o.). As they currently stand, however, neither off-the-shelf theory is capable of fully capturing the behavior of contour tones or contour segments. For these reasons, we advocate $\mathrm{ABC}+\mathrm{Q}$ - that is, the enhancement of $\mathrm{ABC}$ with $\mathrm{Q}$-based representations.

Autosegmental Phonology is driven primarily by individual features or feature bundles, which in the case of harmony spread autonomously from one segment to another. The theory was designed to capture effects that in $\mathrm{Q}$ theory are located at the $q$ level. To represent assimilation, a feature or tone spreads ("links") to nearby timing slots, as shown in (5a). This representation correctly predicts that assimilation can create or be triggered by parts of contours, as spreading occurs between adjacent features and tones. Autosegmental representation, however, struggles with whole contour behavior (e.g., (3)) because contours 
are not units in standard Autosegmental Theory (Duanmu 1994; cf. Yip 1989). Spreading of whole contour tones causes problematic non-adjacent representational linkage, shown in (5b):

\begin{tabular}{|c|c|}
\hline a. $\quad / C V^{\prime C V} / \rightarrow\left[C V^{\prime C V}\right]$ & b. $/ \mathrm{CVCV} / \rightarrow[\hat{\mathrm{CVCV}}]$ \\
\hline$\left.\right|_{\mathrm{H}} ^{\mathrm{C} \mathrm{V}} \mathrm{C} \mathrm{V} \rightarrow[\mathrm{C} \mathrm{V́} \mathrm{C} \hat{\mathrm{V}}]$ & 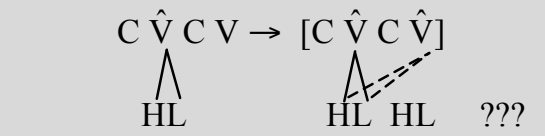 \\
\hline $\begin{array}{l}\text { simple spreading easily produces partial } \\
\text { assimilation (cf. (3c)) }\end{array}$ & $\begin{array}{l}\text { simple spreading cannot produce total } \\
\text { assimilation of contours (cf. (3a)) }\end{array}$ \\
\hline
\end{tabular}

In contrast to Autosegmental Theory, $\mathrm{ABC}$ is a theory whose original formulation is based on segments as whole units. In $\mathrm{ABC}$, corresponding local segment pairs, under conditions of similarity and proximity (CORR-XX), are required to be identical in some respect (IDENT-XX). ABC has been characterized by Inkelas \& Shih (2013b) as diagnosing and resolving 'unstable correspondence', defined as the co-existence of structures which are similar or proximal enough to interact but too uncomfortably similar or proximal to co-exist. Such segments must either assimilate or dissimilate in order to continue to co-exist.

ABC was originally developed for long-distance consonant harmony (Walker 2000a; Hansson 2001; Rose \& Walker 2004; a.o.), and has since found traction in modeling local and long-distance interactions (e.g., Inkelas \& Shih 2013b), including vowel harmony (Sasa 2009; Walker 2009; Rhodes 2012; a.o.), dissimilation (Bennett 2013), and tone phenomena (Shih 2013). Because it targets segments as units, ABC easily models whole segment harmony and disharmony, including between contours as wholes (e.g., 6a), i.e. interactions at what in Q theory is the $Q$ level of representation. The trouble for standard $\mathrm{ABC}$ is partial contour behavior, which comes more naturally to Autosegmentalism. Because partial assimilation does not produce overall segmental identity, partial assimilations do not satisfy ABC identity constraints that operate over corresponding whole $Q$ segments (6b).

\begin{tabular}{|c|c|}
\hline a. $/ \mathrm{CV} C \dot{V} / \rightarrow[\mathrm{CV} \hat{\mathrm{V}}]$ & b. $/ \mathrm{CVCV} / \rightarrow[\mathrm{CVCV}]$ \\
\hline $\mathrm{CV} C \hat{\mathrm{V}}$ does not satisfy CORR \& IDENT & $\mathrm{C} \hat{\mathrm{V}}_{x} \mathrm{C} \hat{\mathrm{V}}_{x}$ satisfies CORR, IDENT \\
\hline $\begin{array}{l}\text { segmental correspondence, segmental identity } \\
\text { can't produce partial assimilation (cf. (3c)) }\end{array}$ & $\begin{array}{l}\text { segmental correspondence, segmental identity } \\
\text { easily produce total assimilation (cf. (3a)) }\end{array}$ \\
\hline
\end{tabular}

The schizoid behavior of both contour tones and contour segments requires a theoretical framework $\mathrm{ABC}+\mathrm{Q}$ - in which contours are accessible to phonological operations both in part and as whole units.

\section{Quantized segments in harmony}

5.1 $Q$ (segmental) correspondence For whole contour harmony in $\mathrm{ABC}+\mathrm{Q}$, constraints mandating correspondence (7b) and agreement (7c) target the $Q$, or segment, level of representation. (7a) illustrates a corresponding pair of $Q$ 's, with correspondence notated by means of identical subscripts. The CORR constraints involved in $Q$ correspondences are given schematically in (7b). Each " $Q$ " in this schema represents a potential natural class of segments - e.g., CORR-CC, CORR-VV, CorR-S[ibilant]S[ibilant], following Hansson (2001), Rose \& Walker (2004); cf. Bennett (2013) and McCarthy (2010). ${ }^{2}$ Following Hansson (2007), CORR constraints are evaluated locally on the closest eligible pairs of $Q$ 's.
a. $\mathrm{Q}_{x}\left(\mathrm{q}^{1} \mathrm{q}^{2} \mathrm{q}^{3}\right) \ldots \mathrm{Q}_{x}\left(\mathrm{q}^{1} \mathrm{q}^{2} \mathrm{q}^{3}\right)$
Pair of corresponding segments
b. CORR-Q $\left(\mathrm{q}^{1} \mathrm{q}^{2} \mathrm{q}^{3}\right) \mathrm{Q}\left(\mathrm{q}^{1} \mathrm{q}^{2} \mathrm{q}^{3}\right)$
Segments meeting a certain threshold of similarity correspond.
c. Ident-QQ-[F]
Corresponding segments agree in feature [F].

\footnotetext{
${ }^{2}$ Hansson (2001) and Rose \& Walker (2004) permit co-indexing of feature values across correspondence classes (e.g. 'homorganic consonants correspond'); Bennett (2013) does not. McCarthy (2010) uses only CoRR-XX constraints in which the value of "X", his equivalent of our "Q", is fixed, always instantiating the entire (consonant) inventory.
} 
IDENT-QQ-[F] is the other ingredient in the basic ABC analysis of $Q$ harmony; it enforces agreement across corresponding $Q$ 's, at each $q$ position, in the feature $[\mathrm{F}]$.

Changzhi (Chinese dialect spoken in Shangxi) provides an example of whole contour correspondence. In Changzhi diminutive formation, seen earlier in $(4 \mathrm{a})$, the entire tonal complex of the root is copied as a whole onto the diminutive suffix [-to ${ }^{2}$ (Yip 1989; Bao 1990; data from Duanmu 1994):

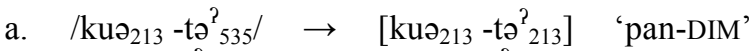
b. $/ \mathrm{sə \eta}_{24}-\mathrm{ta}^{\mathrm{T}}{ }_{535} / \rightarrow\left[\mathrm{s}_{24}-\mathrm{ta}_{24}{ }_{24}\right] \quad$ 'rope-DIM'
c. $/ \mathrm{ti}_{535}-\mathrm{to}^{2}{ }_{535} / \rightarrow\left[\mathrm{ti}_{535}-\mathrm{to}^{\text {? }}{ }_{535}\right] \quad$ 'bottom-DIM'
d. $/ \mathrm{k}^{\mathrm{h}} \mathrm{u}_{44}-\mathrm{t}^{\text {? }}{ }_{535} / \rightarrow\left[\mathrm{k}^{\mathrm{h}} \mathrm{u}_{44}-\mathrm{to}^{\text {? }}{ }_{44}\right] \quad$ 'pants-DIM'
e. $/ \operatorname{tou}_{53}-\operatorname{to}^{?}{ }_{535} / \rightarrow\left[\operatorname{tou}_{53}-\operatorname{to}^{2}{ }_{53}\right] \quad$ 'bean-DIM'

Analyzing the Changzhi diminutives data in the pre-ABC era, Duanmu (1994) argues for a distinction in Autosegmental Theory between tone spreading and tone copying. Because spreading of an entire tonal complex would involve illegal line-crossing in an autosegmental approach (see $\S 4$ ), Duanmu is obliged to appeal to a separate mechanism of copying (or reduplication; see also Chen 2011). Under an ABC-based approach, however, there is no formal distinction between modeling harmony as spreading or as copying ${ }^{3}$. In $\mathrm{ABC}+\mathrm{Q}$, the Changzhi pattern is modeled as agreement in tone specification between $Q$ vowel segments.

The relevant $\mathrm{ABC}$ constraints for Changzhi are given in (9) below. CORR-VV requires correspondence between vowels at the $Q$ level, assigning a violation to any local pairs of vowels that do not correspond. IDENT-VV-V([tone]) mandates agreement in overall tone specification between two corresponding segments and is violated when tonal complexes are not identical on corresponding vowels. Because the constraints target the segmental $Q$ level, agreement is assessed over entire tone contours.
a. CORR-VV
Entire vowels correspond.
b. IDENT-VV-V([tone]) Corresponding vowels are tonally identical (at every position $q$ ).
c. IDENT-IO-V([tone]) Vowels are tonally identical in input and output (at every position $q$ ).

A tableau for [ $\left.\mathrm{ku}_{213}-\mathrm{t}^{2}{ }_{213}\right]$ 'pan-DIM' is given in (10). High-ranking CORR-VV, which mandates surface correspondence between vowels, dooms candidates whose vowels do not correspond (e.g., 10a). High-ranking IDENT-VV requires corresponding vowels to agree in overall surface tone specification; it dooms candidates whose vowels correspond but disagree in tone (e.g., 10b). The successful candidate satisfies both correspondence and identity via tone assimilation, violating low-ranking IDENT-IO-V[tone $]^{4}$.

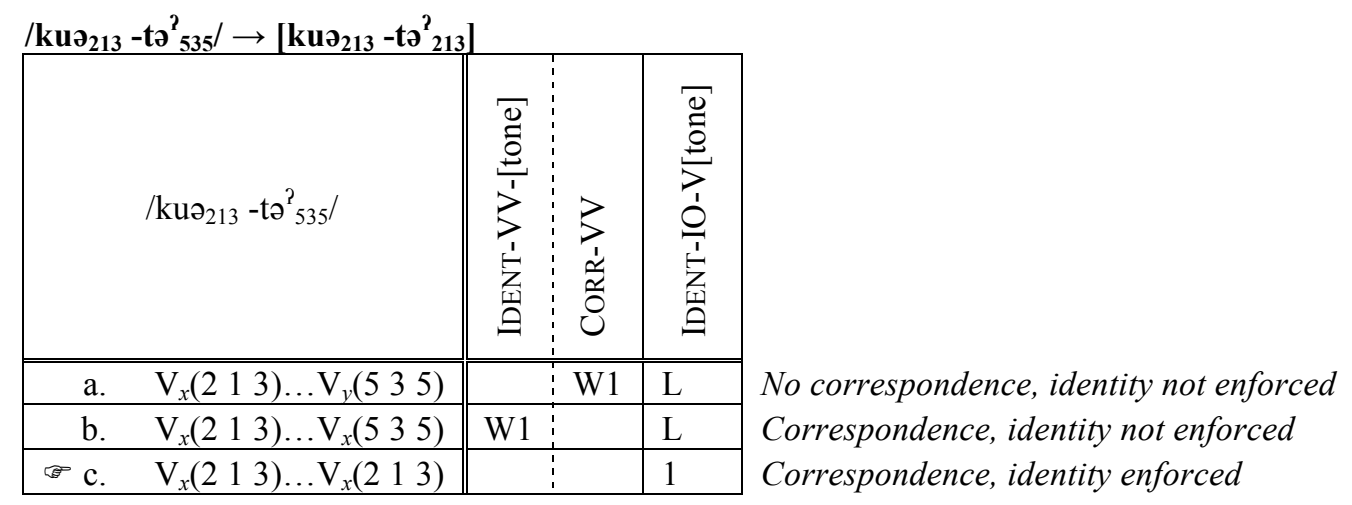

5.2 q (subsegmental) correspondence Prior to $\mathrm{ABC}+\mathrm{Q}$, the challenge for $\mathrm{ABC}$ in capturing contour behavior was how to allow subsegmental parts of contours to behave independently. ABC lacked the representational capacity to refer to units below the segment. The addition of $\mathrm{Q}\left(\mathrm{q}^{1} \mathrm{q}^{2} \mathrm{q}^{3}\right)$ representations in

\footnotetext{
${ }^{3}$ or equivalently, phonological reduplication (see e.g., Inkelas 2008).

${ }^{4}$ Directionality of assimilation can be specified using indexed constraints (in ABC: Hansson 2001; Rose \& Walker 2004) or positional/root faithfulness (in harmony, see e.g., Walker 2001; 2011). Because the issue of directionality is

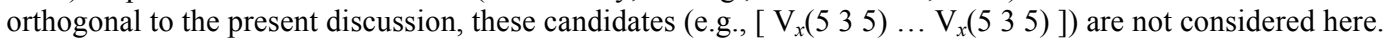


$\mathrm{ABC}+\mathrm{Q}$ resolves this shortcoming. Correspondence and identity constraints can now target not only the $Q$ level (§5.1) but also the subsegmental $q$ level, permitting the analysis of partial contour patterns. Identical subscripts in (11a) denote correspondence between certain subsegments, as specified by CORR-qq. IDENT$\mathrm{qq}-[\mathrm{F}]$ requires that corresponding subsegments agree in feature $[\mathrm{F}]$.
a. $\quad \mathrm{q}_{x} \ldots \mathrm{q}_{x}$
Pair of corresponding subsegments
b. CORR-qq
Subsegments $(q)$ meeting a certain threshold of similarity correspond.
c. IDENT-qq-[F]
Corresponding subsegments agree in feature $[\mathrm{F}]$.

Yoruba (Niger-Congo) exhibits partial contour assimilation in the creation of contour tones (Akinbiyi $\&$ Liberman 2001) $(=3 \mathrm{c})^{5}$. Word-initial tones spread to the second syllable, resulting in a contour:
a. $\mathrm{HL} \rightarrow \mathrm{H} \mathrm{HL}$
/rárà/ $\rightarrow$ [rárâ]
'elegy'
b. $\quad \mathrm{LH} \rightarrow \mathrm{L} \mathrm{LH}$
/àlá/ $\rightarrow$ [àlı̌l
'dream'

The $\mathrm{ABC}+\mathrm{Q}$ approach models these data as tonal assimilation between adjacent $q$ subsegments across a syllable boundary. The relevant constraints for Yoruba and an example tableau are given below ${ }^{6}$ :

a. CORR-q[V]:б:q[V] Vocalic subsegments across a syllable boundary correspond.

b. IDENT-qq-[tone] Corresponding subsegments are tonally identical.

\begin{tabular}{|c|c|c|c|c|}
\hline / V(H H H) ... V(L L L) / & 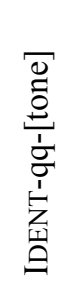 & 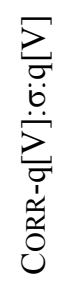 & 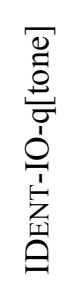 & \\
\hline a. $\quad \mathrm{V}\left(\mathrm{H} \mathrm{H} \mathrm{H}_{x}\right) \ldots \mathrm{V}\left(\mathrm{L}_{y} \mathrm{~L} \mathrm{~L}\right)$ & & W1 & $\mathrm{L}$ & No correspondence \\
\hline b. $\quad \mathrm{V}\left(\mathrm{H} \mathrm{H} \mathrm{H}_{x}\right) \ldots \mathrm{V}\left(\mathrm{L}_{x} \mathrm{~L} \mathrm{~L}\right)$ & W1 & & $\mathrm{L}$ & Correspondence, no identity \\
\hline c. $\quad \mathrm{V}\left(\mathrm{H} \mathrm{H} \mathrm{H}_{x}\right) \ldots \mathrm{V}\left(\mathrm{H}_{x} \mathrm{~L} \mathrm{~L}\right)$ & & & 1 & Correspondence, identity \\
\hline d. $\quad \mathrm{V}\left(\mathrm{H}_{x} \mathrm{H}_{x y} \mathrm{H}_{y z}\right) \ldots \mathrm{V}\left(\mathrm{H}_{z a} \mathrm{H}_{a b} \mathrm{H}_{b}\right)$ & & & W3 & Unnecessary correspondence \\
\hline
\end{tabular}

CORR-q[V]: $\sigma: q[V]$ (13a) enforces surface co-indexation of vocalic $q$ subsegments which are no more than one syllable apart, and penalizes candidate (14a) in the tableau in (14). Tonal identity between corresponding subsegments is required by IDENT-qq-[tone] (13b), ruling out candidates such as (14b), in which the relevant subsegments correspond but disagree in tone specification. Finally, low-ranked inputoutput faithfulness (IDENT-IO-q[tone]) prevents unnecessary correspondence and identity that could otherwise result in complete tone agreement throughout the segment, as in (14d). The candidate which best satisfies the subsegmental, $q$-level correspondence and identity constraints is $(14 \mathrm{c})$, with a contour tone.

\section{Disharmony}

The $\mathrm{ABC}+\mathrm{Q}$ approach to contours in harmony also extends to disharmony phenomena. In $\mathrm{ABC}$, disharmony and harmony are both consequences of correspondence relationships between similar or proximal entities. Bennett (2013) proposes that disharmony can repair correspondence relationships that are too costly to maintain: ifcorrespondence would violate a high-ranking constraint (e.g., XX-EDGE ${ }^{7}$ or IDENT$\mathrm{XX}$ ), the optimal candidate may avoid the violation by escaping the correspondence relationship altogether.

\footnotetext{
${ }^{5}$ For a similar pattern, see Chiquihuitlán Mazatec (Jamieson 1977; Yip 2002).

${ }^{6}$ CORR constraints can be scaled by proximity (Hansson 2001:298), as reflected in (14a). See section 8 for discussion.

${ }^{7}$ XX-EDGE: corresponding segments may not be separated by a prosodic (e.g., syllable) boundary (from Bennett 2013).
} 
Tianjin provides an illustration of the power and flexibility of ABC+Q. As discussed by Chen (1985) and Yip (1989:163; 2002:51, 179), Tianjin exhibits what in ABC+Q terms is simultaneously whole contour $Q$ dissimilation and partial contour $q$ dissimilation. Adjacent whole tones dissimilate at the $Q$ level via contour simplification (15a) or contour creation (15b). Adjacent subsegments ( $q$ ) across a syllable boundary also dissimilate relative to one another $(15 \mathrm{~b}, \mathrm{c})$ :

$$
\begin{aligned}
& \text { a. LH.LH } \rightarrow \text { H.LH *HL.LH } \quad / \mathrm{xi}_{\mathrm{LH}} / \quad \rightarrow \quad\left[\mathrm{xi}_{\mathrm{H}} \cdot \operatorname{lian}_{\mathrm{LH}}\right] \quad \text { 'wash one's face' } \\
& \text { b. L H } \rightarrow \text { L LH *LH.HL /àlá/ } \rightarrow \text { [àlǐ] 'net weight' } \\
& \text { c. L.L } \rightarrow \text { LH.L *HL.L, *L.LH } \quad / \mathrm{fei}_{\mathrm{L}} / \rightarrow \quad\left[\mathrm{fei}_{\mathrm{LH}} \mathrm{ji}_{\mathrm{L}}\right] \quad \text { 'airplane' } \\
& \text { d. HL.L } \rightarrow \text { H.L }
\end{aligned}
$$

An $\mathrm{ABC}+\mathrm{Q}$ analysis of both the $Q$-level and the $q$-level dissimilation is provided in (16), following the general approach of Bennett (2013) to dissimilation in the ABC framework. The first three constraints handle $Q$ level dissimilation. CORR-QQ[tone] ensures correspondence between tonally identical $Q$ 's; QQEdge- $(\sigma)$, a 'delimiter' constraint of the kind invoked in Bennett (2013), penalizes correspondents in

\begin{tabular}{|c|c|c|}
\hline \multirow{4}{*}{ a } & & \\
\hline & CORR-Q: $\sigma: Q[$ tone $]$ & Tonally identical segments in adjacent syllables correspond. \\
\hline & QQ-Edge- $(\sigma)$ & Corresponding segments may not be in adjacent syllables. \\
\hline & IDENT-QQ[tone] & Corresponding segments must be tonally identical. \\
\hline \multirow{3}{*}{$\sigma$} & CORR-q:б:q [tone] & $\begin{array}{l}\text { Tonally identical adjacent subsegments across a syllable boundary } \\
\text { correspond. }\end{array}$ \\
\hline & qq-Edge- $(\sigma)$ & Corresponding segments may not be in adjacent syllables. \\
\hline & IDENT-qq[tone] & Corresponding subsegments must be tonally identical. \\
\hline
\end{tabular}
adjacent syllables. IDENT-QQ[tone] requires correspondents to be tonally identical. A corresponding trio of constraints accounts for $q$ dissimilation across syllable boundaries:

A tableau illustrating the application of these constraints to a level L-toned disyllabic input is shown in (17). Tonally faithful outputs violate the requirements of adjacent $Q$ disharmony and adjacent $q$ disharmony across a syllable boundary. These requirements are satisfied by the winning candidate, $(17 \mathrm{j})$, in which the

\begin{tabular}{|c|c|c|c|c|c|c|c|c|c|}
\hline / V(L L L) ... V(L L L) / & 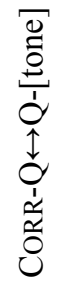 & 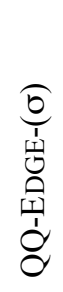 & 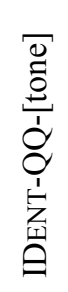 & 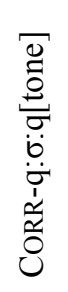 & 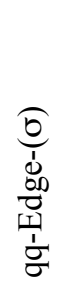 & 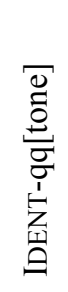 & 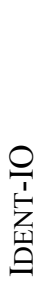 & \multirow{5}{*}{$\begin{array}{l}Q / q \text { corr. } \\
Q \text { corr. only } \\
q \text { corr. only } \\
\text { No corr. }\end{array}$} & \multirow{5}{*}{ 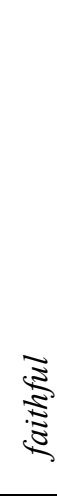 } \\
\hline a. $\quad \mathrm{V}_{a}\left(\mathrm{~L} \mathrm{~L} \mathrm{~L}_{x}\right) \ldots \mathrm{V}_{a}\left(\mathrm{~L}_{x} \mathrm{~L} \mathrm{~L}\right)$ & & W1 & & & W1 & & $\mathrm{L}$ & & \\
\hline b. $\quad \mathrm{V}_{a}\left(\mathrm{~L} \mathrm{~L} \mathrm{~L} \mathrm{~L}_{x}\right) \ldots \mathrm{V}_{a}\left(\mathrm{~L}_{y} \mathrm{~L} \mathrm{~L}\right)$ & & W1 & & W1 & & & $\mathrm{L}$ & & \\
\hline c. $\quad \mathrm{V}_{a}\left(\mathrm{~L} \mathrm{~L} \mathrm{~L} \mathrm{~L}_{x}\right) \ldots \mathrm{V}_{b}\left(\mathrm{~L}_{x} \mathrm{~L} \mathrm{~L}\right)$ & W1 & & & & W1 & & $\mathrm{L}$ & & \\
\hline d. $\quad \mathrm{V}_{a}\left(\mathrm{~L} \mathrm{~L} \mathrm{~L} \mathrm{~L}_{x}\right) \ldots \mathrm{V}_{b}\left(\mathrm{~L}_{y} \mathrm{~L} \mathrm{~L}\right)$ & W1 & & & W1 & & & $\mathrm{L}$ & & \\
\hline e. $\quad \mathrm{V}_{a}\left(\mathrm{~L} \mathrm{~L} \mathrm{H}_{x}\right) \ldots \mathrm{V}_{a}\left(\mathrm{~L}_{x} \mathrm{~L} \mathrm{~L}\right)$ & & W1 & W1 & & W1 & W1 & 1 & \multirow{6}{*}{$\begin{array}{l}Q / q \text { corr. } \\
Q \text { corr. only } \\
q \text { corr. only } \\
q \text { corr. only } \\
\text { No corr. } \\
\text { No corr. }\end{array}$} & \\
\hline f. $\quad \mathrm{V}_{a}\left(\mathrm{~L} \mathrm{~L} \mathrm{H}_{x}\right) \ldots \mathrm{V}_{a}\left(\mathrm{~L}_{y} \mathrm{~L} \mathrm{~L}\right)$ & & W1 & W1 & & & & 1 & &. \\
\hline g. $\quad \mathrm{V}_{a}\left(\mathrm{~L} \mathrm{~L} \mathrm{H}_{x}\right) \ldots \mathrm{V}_{b}\left(\mathrm{~L}_{x} \mathrm{~L} \mathrm{~L}\right)$ & & & & & W1 & W1 & 1 & & $\frac{\pi}{8}$ \\
\hline h. $\quad \mathrm{V}_{a}\left(\mathrm{~L} \mathrm{~L} \mathrm{~L} \mathrm{~L}_{x}\right) \ldots \mathrm{V}_{b}\left(\mathrm{~L}_{x} \mathrm{~L} \mathrm{H}\right)$ & & & & & W1 & & 1 & & . \\
\hline i. $\quad \mathrm{V}_{a}\left(\mathrm{~L} \mathrm{~L} \mathrm{~L} \mathrm{~L}_{x}\right) \ldots \mathrm{V}_{b}\left(\mathrm{~L}_{y} \mathrm{~L} \mathrm{H}\right)$ & & & & W1 & & & 1 & & $: \stackrel{2}{\pi}$ \\
\hline j. $\quad \mathrm{V}_{a}\left(\mathrm{~L} \mathrm{~L} \mathrm{H}_{x}\right) \ldots \mathrm{V}_{b}\left(\mathrm{~L}_{y} \mathrm{~L} \mathrm{~L}\right)$ & & & & & & & 1 & & \\
\hline
\end{tabular}
final $q$ of the first syllable surfaces as H, creating Q disharmony between the first syllable (LH) and the second (L), and $q$ disharmony between the final $\mathrm{H} q$ of the first syllable and the initial $\mathrm{L} q$ of the second: 
6.1 Q/q independence in (dis)harmony Because $\mathrm{ABC}+\mathrm{Q}$ accommodates direct reference to either the segments or subsegments that undergo agreement and disagreement, whole contour and partial contour subsegments can behave independently in their dissimilation and agreement behaviors, even in the same example. Pingyao illustrates this dissociation: adjacent whole tones exhibit $Q$ dissimilation while adjacent $q$ 's must agree. (Hakha Lai exhibits a similar pattern; see Hyman \& VanBik 2002.)

Pingyao (Chen 1992; data from Yip 2002: 196)

a. Adjacent Q tonal dissimilation: hai $_{35}$ bing $_{35} \rightarrow\left[\right.$ hai $_{53}$ bing $\left._{35}\right] \quad$ 'become ill'

b. Adjacent $q$ assimilation: $\quad \mathrm{er}_{53} \operatorname{ruan}_{53} \rightarrow\left[\mathrm{er}_{35} \operatorname{ruan}_{53}\right] \quad$ 'ear soft, i.e. gullible'

These facts can be modeled within $\mathrm{ABC}+\mathrm{Q}$ using constraints similar to those for Tianjin, except that at the $q$ level, there is no EDGE delimiter constraint. As a result, corresponding $q$ 's across a syllable boundary obey CORR-qq and IDENT-qq, exhibiting assimilation rather than dissimilation.

\section{Consequences of similarity: local segment-tone interaction}

In early work in $\mathrm{ABC}$, it was thought that correspondence, with its intrinsic similarity precondition, was suited only for long-distance interactions, and that local assimilation or dissimilation would be accomplished using a different mechanism (e.g., Autosegmentalism) (Hansson 2001; Rose \& Walker 2004). This view has been challenged by recent work arguing that similarity also underlies local segmental interactions and that $\mathrm{ABC}$ is equally suited to these effects (Wayment 2009; Inkelas \& Shih 2013b). As argued by Shih (2013), the similarity basis applies to local tone effects as well. Below, we illustrate a highly local subsegment-to-subsegment tone assimilation pattern in Nupe (Niger-Congo). Like Yoruba, Nupe assimilation creates contours: L spreads to a following H-toned vowel, producing a LH rising contour. However, this occurs only when the intervening consonant is voiced (a sonorant or a voiced obstruent) (George 1970; Yip 2002:143-144):

Nupe: L spreads to following $\mathrm{H}$ only through a voiced consonant (a, vs. b):
a. Spreading:
èdǔ 'taxes'
/è-lé/ $\rightarrow$ [èlě] 'past'

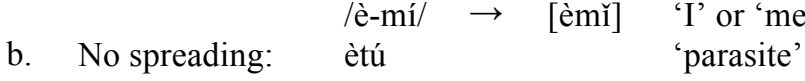

Following the approach taken by Shih (2013) to a comparable segmental $(Q)$ pattern in Dioula d'Odienné, we model Nupe L tone spreading as a highly local, subsegment-to-subsegment interaction: adjacent voiced $q$ subsegments — vowels and consonants alike - must correspond across a segment boundary ("S") and agree in tone specification ${ }^{8}$.
a. $\quad$ CORR-q[+vd]:S:q[+vd]
b. IDENT-qq(tone)
c. FAITH-IO q(tone)
d. CORR-q:S:q
Voiced $q$ correspond across a segment boundary. Corresponding $q$ agree in tone.
Tonal identity required between input and output. All $q$ correspond across a segment boundary.

For an input like /èdú/ (19a), with a voiced intervening consonant, CORR-q[+vd]:S:q[+vd] compels correspondence within both pairs of adjacent segments; as seen in (21c), VC tone assimilation takes place:

\footnotetext{
${ }^{8}$ For expository simplicity, it is assumed here that consonants have L tone. In actuality, the consonantal tones may be unspecified, or they may be prespecified for $\mathrm{L}$ versus $\mathrm{H}$ tone in voiced versus voiceless consonants, respectively, reflecting their cross-linguistic phonetic effects on F0. Crucially, the $\mathrm{ABC}$ analysis does not depend on underlying specification to trigger consonant-tone effects: it is the surface relationship that catalyzes or inhibits vocalic tone spreading. Also for simplicity, it is assumed that consonant-internal subsegments here must bear uniform tone features.
} 


\begin{tabular}{|c|c|c|c|c|c|}
\hline 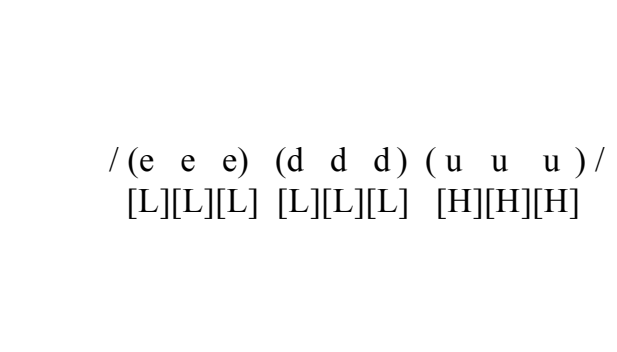 & 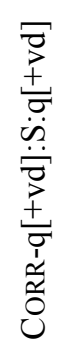 & 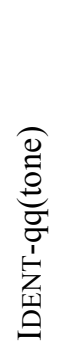 & 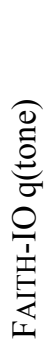 & 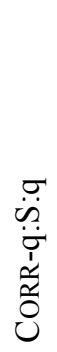 & \\
\hline $\begin{array}{cccccc}\text { a. } & \left(\begin{array}{lllll}\text { e } & \text { e } & \text { e }\end{array}\right) & \left(\begin{array}{llll}\text { d } & \text { d } & d\end{array}\right) & \left(\begin{array}{lll}\text { u } & \text { u } & \text { u }\end{array}\right) \\
& {[\mathrm{L}][\mathrm{L}][\mathrm{L}]} & {[\mathrm{L}][\mathrm{L}][\mathrm{L}]} & {[\mathrm{H}][\mathrm{H}][\mathrm{H}]}\end{array}$ & W2 & & $\mathrm{L}$ & & No corr. \\
\hline 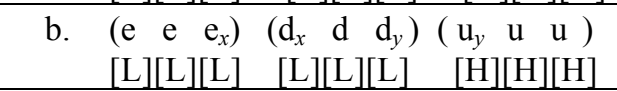 & & W1 & $\mathrm{L}$ & & $q$ corr., no identity \\
\hline 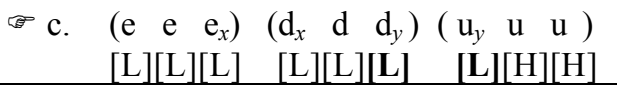 & & & 1 & & q corr., identity \\
\hline
\end{tabular}

For an input like /ètú/ (19b), with a voiceless intervening consonant, CoRR-q[+vd]:S:q[+vd] is inapplicable, and CORR-q:S:q is ranked too low to compel VC or CV correspondence; therefore, VC tone assimilation does not take place:

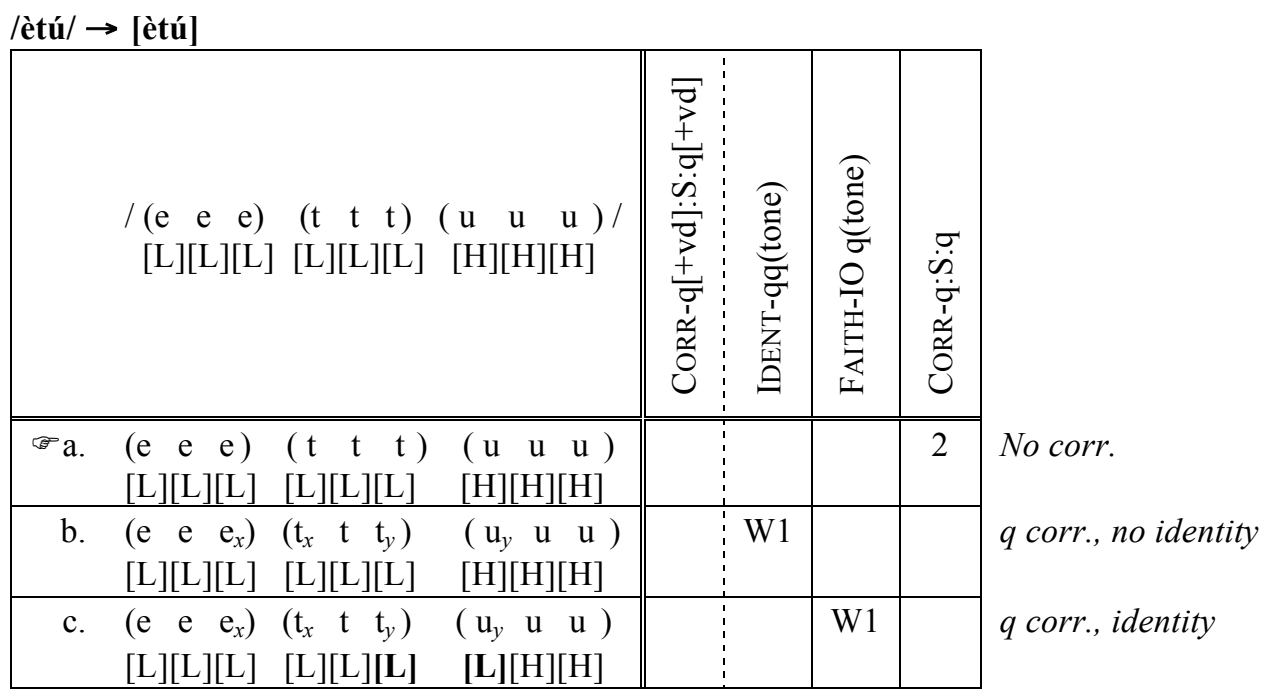

\section{$8 \mathrm{ABC}+\mathrm{Q}$ summarized, vs. autosegmental spreading}

$\mathrm{ABC}+\mathrm{Q}$ is rooted in the principle that similarity and proximity of two entities (subsegments, segments, syllables, strings ${ }^{9}$ ) are positively correlated with the likelihood that they will interact (Walker 2000a; 2000b; Hansson 2001; Rose \& Walker 2004; cf., Bennett 2013). These principles, implemented here by means of intrinsically stringent CORR constraints, are part of the basic architectural design of the theory.

Similarity encoded via stringent CORR constraints:

CORR-XX (segments correspond)

CORR-CC (consonants correspond)

CORR-NT (coronals correspond), CORR-SS (sibilants correspond) ...etc.

\footnotetext{
${ }^{9}$ On phonologically motivated string-to-string correspondence, see e.g. Zuraw (2002), a predecessor to ABC; as well as Yu (2005) and Inkelas (2008).
} 
Stringency follows simply from the fact that CORR constraints place natural classes of segments in corresondence with one another. If two segments that agree in features [A] and [B] but differ in features [F] and $[\mathrm{G}]$ are compelled by a CORR constraint to correspond, it follows automatically that two segments which agree in $[\mathrm{A}],[\mathrm{B}]$, and $[\mathrm{F}]$ (or in $[\mathrm{A}],[\mathrm{B}]$, and $[\mathrm{G}]$, or in $[\mathrm{A}],[\mathrm{B}],[\mathrm{F}]$, and $[\mathrm{G}]$ ) will also correspond.

Proximity, alluded to above, is also a scalar effect and can be implemented via constraints. The most predictive implementation uses stringent constraints, meaning that compelling correspondence at some larger distance $D$ necessarily also compels correspondence at any smaller distance. Following Hansson (2001), we assume constraints like those in (24). CORR-X: $\infty: X$, also abbreviated as CORR-X↔X, is the least restrictive, requiring correspondence at any distance. CORR-X::X is the strictest: only string adjacent segments must correspond. In between are constraints like CORR-X: $\mu: X$, requiring correspondence between units separated by no more than one mora boundary, and CORR-X: $\sigma: X$, requiring correspondence between units separated by no more than one syllable boundary. See e.g., Hansson 2001; Rose \& Walker 2004; Inkelas \& Shih 2013b for discussion. (Notation varies; we follow Inkelas \& Shih (2013b) here.) The constraints illustrated in (24) refer, for the sake of illustration, to sibilant correspondence; of course, proximity scales and similarity scales are completely orthogonal.

$$
\begin{aligned}
& \text { Proximity encoded via stringent CORR constraints: } \\
& \text { CORR-S: } \infty: \mathrm{S} \text { (=CORR-S } \leftrightarrow \mathrm{S}) \text { (sibilants correspond at any distance) }
\end{aligned}
$$

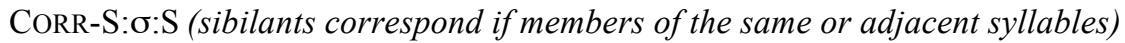

$$
\begin{aligned}
& \text { CORR-S: } \mu: \mathrm{S} \text { (sibilants correspond if members of the same or adjacent moras) } \\
& \text { CORR-S::S (consonants correspond if strictly adjacent) }
\end{aligned}
$$

In incorporating the principles of similarity and proximity via stringent constraints, $\mathrm{ABC}+\mathrm{Q}$ has an advantage over Autosegmental Theory, in which similarity and proximity conditions can be stipulated but do not follow from precepts of the theory, and in which similarity and proximity are not stringent conditions. In $\mathrm{ABC}+\mathrm{Q}$, if a pair of segments correspond (and undergo some ensuing interaction) at a given distance and degree of similarity, the theory predicts that any pair of segments which are more similar, or closer, will also correspond (and exhibit the same interaction). In Autosegmental Theory, this consequence does not follow.

In Autosegmental approaches, for example, natural-seeming similarity conditions on assimilation can be stipulated ${ }^{10}$ — but so can perverse dissimilarity conditions. In (25), for example, we see two reasonablelooking autosegmental rules, one $(25 \mathrm{a})$ spreading [ $+\mathrm{rd}]$ to a [+high] vowel if the trigger is itself [+high], and another $(25 \mathrm{~b})$ spreading [ $+\mathrm{rd}]$ to a [+high] vowel if the trigger is itself [-high]. The rule in (25a) representing a common alternation - requires preexisting similarity between trigger and target; the rule in (25b) - representing an alternation which is unattested, to our knowledge - applies only when the trigger and target are dissimilar. (25b) is impossible to translate into $\mathrm{ABC}(+\mathrm{Q})$. While $\mathrm{ABC}(+\mathrm{Q})$ can compel correspondence (and harmony) between dissimilar vowels, any such requirement will also necessarily apply to more similar vowels; compelling correspondence only between dissimilar vowels is not possible.

\begin{tabular}{|c|c|}
\hline a. 'Natural' (similarity-based) & b. 'Perverse' (not similarity-based) \\
\hline [hi] & ..hi] [+hi] \\
[rd] & [rd] $]$ \\
\hline a high vowel assimilates only to another \\
high vowel in rounding
\end{tabular}

Similar reasoning holds for proximity. Autosegmental Theory can stipulate that structures at a given distance from one another will interact, but it does not follow from the intrinsic principles of Autosegmental Theory that closer structures will also interact, as is the case in $\mathrm{ABC}(+\mathrm{Q})$.

\footnotetext{
${ }^{10}$ See Padgett $(1994,1995 a)$ for an attempt to build certain kinds of trigger-target similarity into Autosegmental theory by using Feature Geometry (Clements 1985; Sagey 1986) to force featural parasitism. However, Padgett (1995b) abandons this approach, arguing that Feature Geometry is too rigid for the range of effects found cross-linguistically.
} 


\section{Conclusion}

$\mathrm{ABC}+\mathrm{Q}$ has an advantage over previous accounts in capturing the schizoid, dualist behavior of contour tones (and, by extension, contour segments, not discussed for lack of space; see Inkelas \& Shih 2013a). Contour tones can behave as units, triggering or undergoing assimilation or dissimilation in their entirety. Yet the components of contours can also behave independently of the whole. $\mathrm{ABC}+\mathrm{Q}$ incorporates the subsegmental architecture needed to account for this dualism. Like the larger segments containing them, subsegments can be targeted for correspondence relationships in harmony and disharmony patterns. Positing subsegments permits the duality of contour behavior to be modeled in tonal and segmental domains, and unites segments and tone under a single treatment for harmony and disharmony.

The main insight behind all $\mathrm{ABC}$ analyses is that correspondence (and ensuing alternation) is conditioned on similarity and proximity. These principles are quite familiar in the segmental domain; we have shown in this paper that they apply equally to tone. In Yoruba and Nupe, we saw examples of proximal subsegments which were proximal enough to interact, yet not identical; tone assimilation achieved the necessary stability. We also observed, in Tianjin and Pingyao, identical tone contours in too close proximity to one another. Dissimilatory alternations reduced the overall similarity between the contours, avoiding correspondence. Extensions of this idea may shed light on the typology of contour tones in languages like Yoruba in which Mid tone cannot contour with $\mathrm{L}$ or H $\left({ }^{*} \mathrm{ML},{ }^{*} \mathrm{MH},{ }^{*} \mathrm{HM},{ }^{*} \mathrm{ML}\right.$ vs. $\checkmark \mathrm{LH}$, $\checkmark$ HL (Akinbiyi \& Liberman 2001). Dispersion is a repair for unstable subsegmental correspondence.

The $\mathrm{ABC}+\mathrm{Q}$ approach to tone brings the analysis of tone much closer to that of segmental phonology. This is a departure from the past, in which tone, as the outlier, prompted the development of a new model of phonology (Autosegmental theory), which was subsequently seen to shed light on segmental effects. In this case, we have taken a theory of both long-distance and local segmental phonology and shown that it improves our ability to handle the behavior of tone. Regardless of the path taken, however, it is clear that tone and segmental phonology exhibit enough parallels - and intimately interact with one another, as in Nupe - for it to be desirable to handle both using the same theoretical devices. In this paper, the theoretical device in question is $\mathrm{ABC}$, augmented with $\mathrm{Q}$ representations: $\mathrm{ABC}+\mathrm{Q}$.

\section{References}

Akinbiyi, Akinlabi \& Mark Liberman. 2001. Tonal complexes and tonal alignment. In Minjoo Kim \& Uri Strauss (eds.), Proceedings of NELS 31, 1-20.

Applegate, Richard B. 1972. Inseño Chumash grammar. Berkeley, CA: UC Berkeley Ph.D. dissertation.

Bao, Zhi-ming. 1990. On the Nature of Tone. Cambridge, MA: MIT Ph.D. dissertation.

Bateman, Janet. 1990. Iau segmental and tonal phonology. Miscellaneous studies of Indonesian and other languages in Indonesia, vol. 10, 29-42.

Bennett, William G. 2013. Dissimilation, consonant harmony, and surface correspondence. New Brunswick, NJ: Rutgers University Ph.D. dissertation.

Browman, Catherine P. \& Louis Goldstein. 1989. Articulatory Gestures as Phonological Units. Phonology 6(2). 201251.

Chen, Matthew Y. 1985. Tianjin tone sandhi: erratic rule application. San Diego, CA: UC San Diego, Ms.

Chen, Matthew Y. 1992. Tone rule typology. Proceedings of the 18th Annual Meeting of the Berkeley Linguistic Society: Special Session on the Typology of Tone Languages, 54-66. Berkeley, CA.

Chen, Tsung-Ying. 2011. Changzhi suffix tonal reduplication. Proceedings of the 34th Annual Penn Linguistics Colloquium. 17(1): 51-60. University of Pennsylvania. http://repository.upenn.edu/cgi/viewcontent.cgi? article $=1167 \&$ context $=$ pwpl.

Clements, G. N. 1985. The geometry of phonological features. Phonology Yearbook 2. 225-252.

Dindelegan, Gabriela P. (ed.). 2013. The grammar of Romanian. Oxford, UK: Oxford University Press.

Duanmu, San. 1994. Against Contour Tone Units. Linguistic Inquiry 25(4). 555-608.

Gafos, Adamantios I. 2002. A Grammar of Gestural Coordination. NLLT 20(2). 269-337.

George, Isaac. 1970. Nupe tonology. Studies in African Linguistics 1. 100-122.

Goldsmith, John. 1976. Autosegmental phonology. Cambridge, MA: MIT Ph.D. dissertation.

Golston, Chris \& Wolfgang Kehrein. 1998. Mazatec Onsets and Nuclei. IJAL 64(4). 311-337.

Hansson, Gunnar Ólafur. 2001. Theoretical and Typological Issues in Consonant Harmony. Berkeley, CA: UC Berkeley Ph.D. dissertation.

Hansson, Gunnar Ólafur. 2007. Blocking Effects in Agreement by Correspondence. Linguistic Inquiry 38(2). $395-409$.

$\mathrm{Hu}$, Wei. 2011. Production and perception of double contour tones in Qiyang Chinese. Paper presented at the IchPhS XVII, Hong Kong. http://www.icphs2011.hk/resources/OnlineProceedings/RegularSession/Hu/Hu.pdf. 
Hualde, Jose. 1987. On Basque affricates. In Megan Crowhurst (ed.), Proceedings of the 6th West Coast Conference on Formal Linguistics. Stanford, CA: Stanford Linguistics Assocation.

Hyman, Larry M. 2009. Tonal morphology: is it different? Paper presented at the Conference on Morphology of the World's Languages, Leipzig, Germany. http://www.uni-leipzig.de/ exponet/mowl/Handouts/Hyman.pdf.

Hyman, Larry M. \& Kenneth VanBik. 2002. Tone and syllable structure in Hakha-Lai. Proceedings of the 28th Annual Meeting of the Berkeley Linguistic Society, 15-28. Berkeley, CA.

Inkelas, Sharon. 2008. The dual theory of reduplication. Linguistics 46(2). 351-401.

Inkelas, Sharon \& Stephanie S Shih. 2013a. Contour segments and tones in (sub)segmental Agreement by Correspondence. Paper presented at the 21st Manchester Phonology Meeting, University of Manchester, UK.

Inkelas, Sharon \& Stephanie S Shih. 2013b. Unstable surface correspondence as the source of local conspiracies. Paper presented at NELS 2013, University of Connecticut.

Jamieson, Allan R. 1977. Chiquihuitlán Mazatec phonology. SIL International Publications in Linguistics 54. 93-105. Texas: SIL and the University of Texas at Arlington.

Leben, Will. 1978. The representation of tone. In Victoria Fromkin (ed.), Tone: A Linguistic Survey, 177-219. New York: Academic Press.

Leben, William R. 1973. Suprasegmental phonology. Cambridge, MA: MIT Ph.D. dissertation.

McCarthy, John J. 2010. Agreement by Correspondence without CORR constraints. University of Massachusetts, Amherst, Ms. http://works.bepress.com/john_j_mccarthy/106.

McConvell, Patrick. 1988. Nasal cluster dissimilation and constraints on phonological variables in Gurindji and related languages. In Nicholas Evans and Steven Johnson (eds.), Aboriginal Linguistics 1, 135-165. Armidale: University of New England.

Morén, Bruce \& Elizabeth Zsiga. 2006. The lexical and post-lexical phonology of Thai tones. NLLT 24. 113-178.

Pike, Kenneth \& E. Pike. 1947. Immediate constituents of Mazatec syllables. IJAL 13. 78-91.

Remijsen, Bert. 2013. Tonal alignment is contrastive in falling contours in Dinka. Language 89(2). $297-327$.

Rhodes, Russell. 2010. Vowel Harmony as Agreement by Correspondence. (UC Berkeley Phonology Lab Annual Report). UC Berkeley. http://linguistics.berkeley.edu/phonlab/annual_report/annual_report_2012.html.

Rose, Sharon \& Rachel Walker. 2004. A Typology of Consonant Agreement by Correspondence. Language 80(3). $475-531$.

Sagey, Elizabeth C. 1986. The representation of features and relations in non-linear phonology. Cambridge, MA: MIT Ph.D. dissertation.

Sasa, Tomomasa. 2001. Ilokano geminates and compensatory lengthening: An OT account. Iowa City, IA: University of Iowa.

Shih, Stephanie S. 2013/submitted. Consonant-tone interaction as Agreement by Correspondence. Stanford University and UC Berkeley, Ms. http://stanford.edu/ stephsus/shih-ctoneABC-draftms_1-18-13.pdf.

Steriade, Donca. 1993. Closure, release, and nasal contours. In Marie K. Huffman \& Rena Krakow (eds.), Nasals, nasalization, and the velum, 401-470. (Phonetics and Phonology 5). San Deigo, CA: Academic Press.

Steriade, Donca. 1994. Complex onsets as single segments. In Jennifer Cole \& Charles Kisseberth (eds.), Perspectives in Phonology, 202-291. Stanford: CSLI.

Walker, Rachel. 2000a. Long-distance Consonantal Identity Effects. In Roger Billerey \& Brook Danielle Lillehaugen (eds.), Proceedings of WCCFL 19, 532-545. Somerville, MA: Cascadilla Press.

Walker, Rachel. 2000b. Yaka nasal harmony: Spreading or segmental correspondence? Proceedings of the 26th Annual Meeting of the Berkeley Linguistics Society: General Session and Parasession on Aspect, 321-332.

Walker, Rachel. 2001. Round Licensing, Harmony, and Bisyllabic Triggers in Altaic. NLLT 19(4). 827-878.

Walker, Rachel. 2009. Similarity-sensitive blocking and transparency in Menominee. Paper presented at the 83rd Annual Meeting of the Linguistic Society of America, San Francisco, California. http://wwwbcf.usc.edu/ rwalker/MenomineeLSAHdt.pdf.

Walker, Rachel. 2011. Vowel patterns in language. Cambridge, UK: Cambridge University Press.

Wayment, Adam. 2009. Assimilation as attraction: Computing distance, similarity, and locality in phonology. Baltimore, MD: Johns Hopkins University Ph.D. dissertation.

Yip, Moira. 1989. Contour tones. Phonology 6(1). 149-174.

Yip, Moira. 2002. Tone. Cambridge, UK: Cambridge University Press.

$\mathrm{Yu}$, Alan C. L. 2005. Toward a Typology of Compensatory Reduplication. Proceedings of the 24th West Coast Conference on Formal Linguistics, 397-405. Cascadilla Proceedings Project.

Zhang, Jie. 2001. The effects of duration and sonority on contour tone distribution: Typological survey and formal analysis. Los Angeles, CA: UCLA Ph.D. dissertation.

Zuraw, Kie. 2002. Aggressive reduplication. Phonology 19(3). 395-439. 